\title{
Editorial - From the New President
}

Volker Mehrmann, President of the EMS

Dear colleagues,

I wish to address a warm welcome to all members of the EMS, and I want to thank the EMS council for their trust in electing me the new president. Let me begin by thanking the past president, Pavel Exner, for his tireless work for the society in the past four years and also before that. Having served on the Executive Committee for six years and as vice president of the EMS for two years I can really appreciate his great efforts, and as I said when we had our last EC meeting in Barcelona, I am really hoping to count on him for many future activities connected with the EMS and also in dealing with the high politics in Brussels and in the countries of the member societies. I am looking forward to working for the society and hope I can live up to the high standards that Pavel has set. I am sure that this ambition will be well supported by the Executive Committee and the other highly active committees of the EMS.

The EMS is a very well-functioning society with a clear focus on improving the advancement of mathematics in all its aspects of research, education, and advancement of young scientists. This includes improvements in diversity, the popularization of mathematics in society, and proper scientific conduct in research, publication, or evaluation of scientific quality. Another important topic in a continent as highly diverse as Europe is to improve opportunities for mathematical research in economically less favoured countries. In all these areas the EMS has strongly active committees whom I would like to thank already for their past and future work for the society and the mathematical community as a whole.

Although the society is doing well, there is always room for improvement and there are major challenges on the horizon; some of them were addressed in the last editorial by Pavel Exner, but they are so important that I will mention them again.

Mathematical research and education in Europe is highly unbalanced across the continent. This is mostly due to the economic imbalance in Europe but also to the different appreciation of mathematics in different parts of Europe. In general, research funding for mathematics in the EU is too low and extremely unbalanced on a national but also European level. The whole community has to work together to change this. We cannot accept that the European Commission thinks that mathematical research funding via the ERC is sufficient, while other funding streams treat mathematics rather badly. This criticism should not diminish the great support by the ERC, but rather should address the neglect of mathematics in other EU funding programs. However, we should also be aware that in the past this has partly been our own fault. As mathematicians in leading positions or in receipt of important awards, we should speak out for the whole

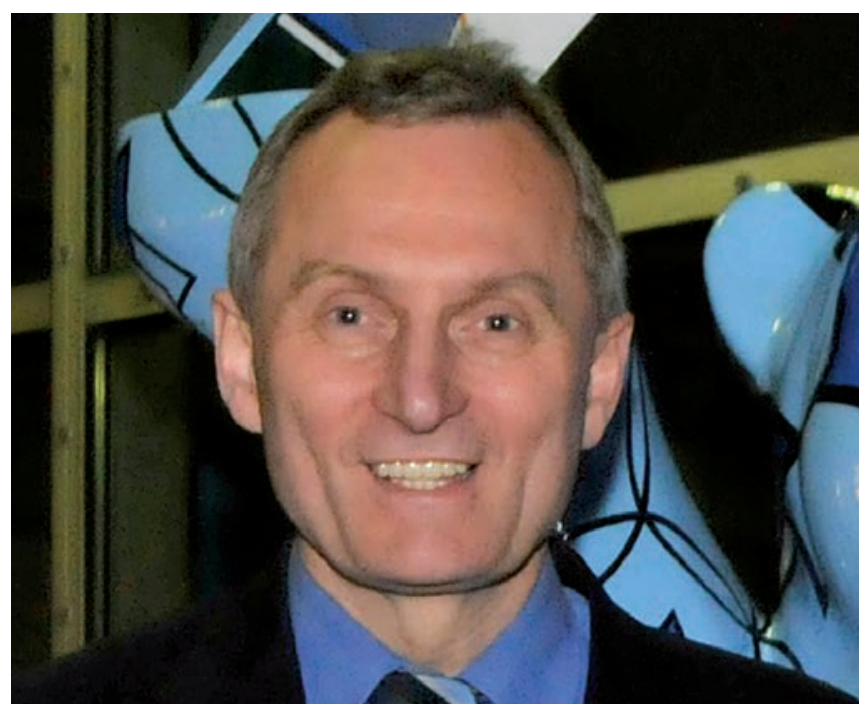

community and appreciate not only the top success stories in mathematics but also the great research work in not-so-prominent areas of mathematics, and proudly advertise it. To achieve this goal it is necessary that we communicate better between the different fields of mathematics (be they more theoretical or more applied) and that we treat each other with more respect than in the past. The mathematics community should work strongly together in lobbying for the advancement of mathematics in Europe: this includes participation in open consultations, or in the EU commission in discussions with ministries and stakeholders on a national level.

A second issue where we should become more active is the advancement of young mathematicians. Currently, the job opportunities in academia and industry for students who finish with a masters or PhD degree are good in highly industrialized European countries, but are generally very unevenly distributed across the whole of Europe. To change this, a major effort within the mathematics community is needed. We should prepare more mathematicians for academia and industry. One way the EMS can help is to sponsor more summer schools on important research topics. However, the community should become active and send in more applications (currently, most EMS-sponsored events have very few applicants) and we should also make an effort to increase the international visibility of our young colleagues.

Mathematical publications are an important part of our activities. The great work of the EMS Publishing House has to be continued after the retirement of the Managing Director Thomas Hintermann but also many new developments have to be taken into consideration. The EMS PH will change its status in the coming weeks and become a limited company owned by the EMS, and a new managing director will be hired (see the adver- 
tisement below). In view of the fact that publishing is becoming more and more electronic, the current publishing models will have to be rethought, and this will be a major activity for the EMS in the coming years. This also concerns the current open-access strategies of the EU and the member states, which will have a huge effect on mathematical publishing in the future. This topic must be a major issue in our discussions with our national governments and with the EU, and we should be prepared to participate in these activities with strong quality control to achieve a sustainable solution. Another issue that is going in a similar direction is the FAIR (Findable, Accessible, Interoperable, Reusable) principle for the availability of mathematical data, where the EMS will have to take a significant role.

Applied and industrial mathematics is strong in some countries but very weak in others, and the EMS together with ECMI (the European Consortium for Mathematics in Industry) has founded the EU-MATHS-IN network (https://www.eu-maths-in.eu/EUMATHSIN/), which has the mission of leveraging the impact of mathematics on innovations in key technologies by enhanced communication and information exchange among the involved stakeholders on a European level. It will act as facilitator, translator, educator, and link between the various players and their communities in Europe.

Furthermore, interdisciplinary communication and cooperation with other sciences still needs to be improved. Last year this cooperation was intensified within the Year of Mathematical Biology, but with other fields of science these links certainly need stronger attention.

Finally, we are all complaining that mathematical education is getting worse in Europe. The whole community has to make major efforts to avoid further degradation of standards and to improve not only general mathematical education, but also that of highly talented young people.
To achieve this it is in my opinion essential to involve more young scientists in the bodies of the community, to support initiatives by young researchers, and to increase the popularity of mathematics in schools, universities, and society as a whole. Please participate in the survey launched by the education committee (http://euro-mathsoc.eu/news/19/02/15/survey-ems-education-committee).

I am looking forward to four years of working together with you for the well-being of mathematics in Europe.

Volker Mehrmann received his Diploma in mathematics in 1979, his PhD in 1982, and his habilitation in 1987 from the University of Bielefeld, Germany. He spent research years at Kent State University in 1979-1980, at the University of Wisconsin in 1984-1985, and at the IBM Research Center in Heidelberg in 1988-1989. After spending the years 1990-1992 as a visiting full professor at the RWTH Aachen, he was a full professor at TU Chemnitz from 1993 to 2000. Since then he has been a full professor of mathematics at TU Berlin.

He is a member of acatech (the German academy of engineering) and the Academia Europaea, he was the president of GAMM (the International Association of Applied Mathematics and Mechanics), vice president of the European Mathematical Society (EMS), chair of MATHEON (the Mathematics for Key Technologies Research Center), and chair of the Einstein Center ECMath in Berlin. He has been president of the EMS since January 2019.

He is a SIAM Fellow, has held an ERC Advanced Grant, and was also a member of the ERC Mathematics Panel. He is an editor of several journals in numerical analysis and editor-in-chief of Linear Algebra and its Applications. His research interests are numerical mathematics/scientific computing, applied and numerical linear algebra, control theory, and the theory and numerical solution of differential-algebraic equations. 